Document downloaded from:

http://hdl.handle.net/10251/103282

This paper must be cited as:

Mars, L.; Ruiz Sánchez, T. (2017). Determinants of elimination decisions in the activity scheduling process. Transportation Letters. doi:10.1080/19427867.2016.1242882

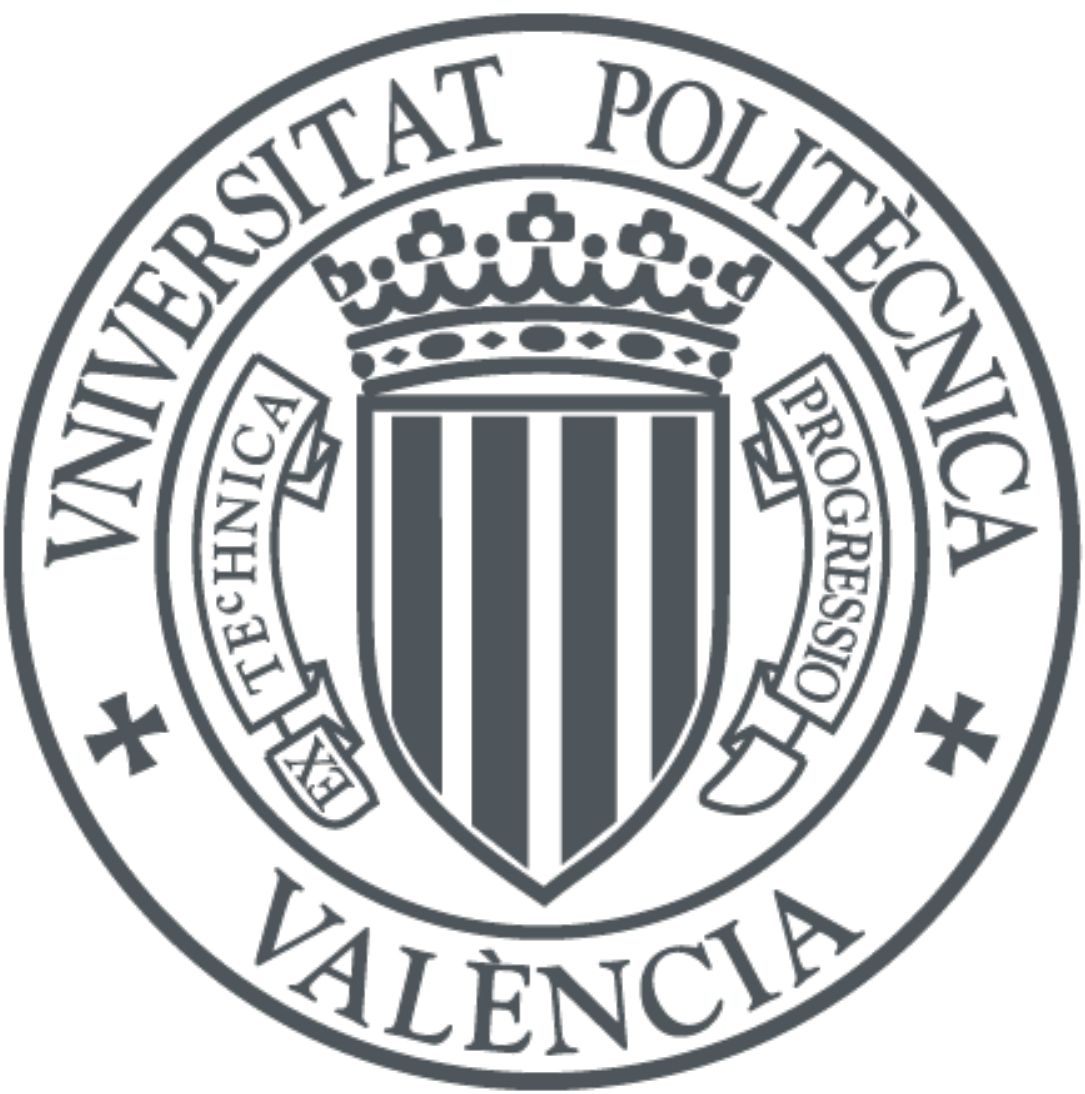

The final publication is available at

https://doi.org/10.1080/19427867.2016.1242882

Copyright Taylor \& Francis

Additional Information 


\section{Determinants of Elimination Decisions in the Activity Scheduling Process}

Lidón Mars ${ }^{\mathrm{a}^{*}}$ and Tomás Ruiz

${ }^{a}$ Researcher, Social Psychology Department, Faculty of Psychology, Universitat de València Avenida Blasco Ibáñez, 21, 46010 Valencia, Spain,

Tel: (+34) 963983940, Fax: (+34) 963877370, Email: m.lidon.mars@uv.es

${ }^{\mathrm{b}}$ Associate Professor, Transport Department, School of Civil Engineering, Universitat Politècnica de València, Camino de Vera s/n, 46022 Valencia, Spain

Tel: (+34) 963877370, Fax: (+34) 963864668, Email: truizsa@tra.upv.es

*Corresponding author 


\title{
Determinants of Elimination Decisions in the Activity Scheduling Process
}

\begin{abstract}
This paper presents an analysis on the determinants related to a particular rescheduling decision in the activity-travel scheduling process: elimination decisions, which consist in the non-execution of preplanned activity-travel episodes. Data used come from an in-depth Computer Assisted Telephone Interview follow up survey carried out during the implementation of the first wave of an activity scheduling process panel survey. Open-ended answers related to the reasons associated to changes between pre-planned and executed agenda are studied. First, an interpretative qualitative method based on Analytic Induction is used to cope with the complex nature of the rescheduling decision under study and the characteristics of the available data. Then, econometric models are used to analyze factors influencing those decisions and complement the qualitative analysis.

The detailed qualitative and quantitative study of those decisions has resulted in the identification of several reasons associated to the elimination of activity-travel episodes from the activity agenda. Factors influencing those reasons have been explored.
\end{abstract}

Keywords: activity scheduling process; qualitative analytic induction; activity-based analysis; activity rescheduling decisions; qualitative and quantitative study

\section{Introduction}

Over the past years, activity travel planning and rescheduling behavior has been of interest to transportation researchers due to its relevance to the congestion management effectiveness and intelligent transportation systems (Lee and McNally, 2006). For instance, the analysis of short and medium term rescheduling decisions are important to resolve route choice problems. They also have a central role in the activity scheduling process. The success of policies such as tolling, congestion pricing, and travel demand management depends on how 
people would adjust their daily activity and travel patterns to the enforced changes in their everyday lives (Axhausen and Gärling, 1992). The investigation of scheduling and rescheduling behavior has been recognized as playing a key role in future modeling efforts (Ruiz and Timmermans, 2008).

In the context of this study, trips (or travels) are displacements from one place to another in order to carry out activities. It is generally accepted that the execution of activities and trips are the result of a complex scheduling process in which activity episodes are inserted, deleted, and modified (Doherty, 2006). The objective of this paper is to study the reasons behind those changes, which would improve our understanding of the activity scheduling process, and help in designing more efficient sustainable transportation policies. What follows is a literature review with the objective of identifying potential rescheduling reasons. First, seminal works in which the activity-based approach is founded and existing behavioral theories are reviewed. Then, the literature that presents studies of rescheduling behavior in the activity-travel scientific area using empirical data is also reviewed. Finally, the use of a qualitative and quantitative approach is justified and described.

\subsection{Theoretical Frameworks on Rescheduling Decisions}

Most theoretical frameworks developed and applied to the problem of short and medium-term rescheduling travel decisions are based on the activity-based approach: travel is a derived demand resulting from the need to pursue activities distributed in space. The original work providing the foundation of the activity-based approach can be dated back to Hägerstrand (1970). He drew attention to the fact that people's choices may be strongly affected by various types of constraints. In particular, he differentiated among capacity, coupling and authority constraints. Capacity constraints have a biological or instrumental origin. For 
example, sleeping, eating and drinking occur in regular rhythms and intervals. Coupling constraints stem from the fact that activities often are conducted jointly with others. Finally, authority constraints such as possession of a driver's license and opening hours constrain when and where someone can conduct a particular activity. In contrast to Hägerstrand, Chapin (1974) stated that individual decisions are made based on propensity and opportunity that become on predisposition factors, like obligations or personal traits, which will result in the performing of certain trips or activities.

Subsequently, Cullen and Godson (1975) presented the activity scheduling process for the first time, where people's main activities acts like anchors around which other activities are sorted and shifted around according to their flexibility. The authors introduced this concept, flexibility, to explain the likelihood of rescheduling associated to activities and travel episodes. More flexible activities are pre-planned and not executed, or can be carried out without any pre-planning, or adapted prior to execution. In contrast, less flexible activities need to be pre-planned in advance, and they usually are carried out without any modification because they have a fixed time and space to be carried out.

On the other hand, some behavioral theories exist that intent to explain how people make decisions and behave consequently. Behavioral Decision Theory describe the need to make choices when there are many attributes to compare (Einhorn and Hogarth, 1981). Social Cognitive Theory (Bandura, 1977) explains human behavior as an interaction of personal factors (cognitive, affective and biological factors), behavior, and the external environment

\subsection{Empirical Studies on Rescheduling Decisions}

The empirical study of activity-travel rescheduling behavior has been carried out using stated responses on how individuals would change their travel behavior in hypothetical scenarios related with facing delays (Roorda and Andre, 2007; Nijland et al., 2009; Habib et al. 2013; 
Chen et al. 2004), congestion charging (Janssens et al., 2009), or weather forecasts (Cools and Creemers, 2013). Other studies used attitudinal data to explore the likelihood of switching from private vehicle to public transit (Chen and Chao, 2011) or related to previous travel adaptation strategies (Cao and Mokhtarian, 2005).

On the other hand, several studies have used observed changes from activity scheduling process data, comparing pre-planned and executed activities and trips. For example, rescheduling activities and trips to resolve scheduling conflicts have been analyzed extensively (Roorda and Miller, 2005; Joh et al., 2005; Ruiz et al., 2005; Ruiz and Timmermans, 2006a, 2006b, 2008; Auld et al., 2009). Van Bladel et al. (2009) proposed a model to analyze the factors that affect activity rescheduling, and found that the effect of performing activities together with other people may affect the rescheduling process and on a further step, unlike the number of accompanying people, the presence of non-household members was an influential variable. Ruiz and Roorda (2011) also studied the likelihood of modification of pre-planned activities and travels. They found that the likelihood of modification of activities are related to different individual, household and activity-travel related factors according to the type of the activity.

Using stated responses or activity scheduling process data, the (re)scheduling of daily or weekly activity-travel agenda has been conceptually or empirically analyzed using dynamic models (Doherty et al. 2002; Auld and Mohammadian, 2009, 2012; Habib, 2011; Yang, 2013, Kademi, 2015).

Finally, Clark and Doherty (2009) is the only study that did not use stated nor observed rescheduling activity-travel behavior. They analyzed the reasons explicitly provided by respondents to add, delete or to modify time attributes of activities and trips between preplanning and executing. In contrast with all the previous studies, this latter research used a qualitative method of analysis to get a deeper understanding of the rescheduling decisions. 
They applied a qualitative content analysis to study the answers provided to four open questions related to changes between the pre-planned schedule described in the initial interview and the executed schedule. They classified causes to add/delete/modify activities into several groups, including: interpersonal factors, conflict/scheduling issues, personal need, personal choice, flexibility, outside factors and convenience.

In all the studies that used activity scheduling process data, changes between the preplanned and the executed schedule were not only determined by a single factor, but by a combination of interacting factors some of which are really difficult to measure. This is why it was decided to collect open-ended questions about the reasons associated to those changes in a follow up Computer Assisted Telephone Interview (CATI) survey included in each wave of an activity scheduling panel survey carried out in Valencia, Spain (Ruiz and GarcíaGarcés, 2014). Those questions allowed people to express their thoughts with little interference by the interviewer and without the bias of a survey that has close-ended answers through the use of predefined choices. The information collected in that survey effort is analyzed in this paper. In particular, the data studied are the reasons associated to a single scheduling decision: not carry out a pre-planned activity or trip. Therefore, both qualitative and quantitative approaches focus on studying that single decision using a static approach.

\subsection{Qualitative and Quantitative Approach to Study Rescheduling Decisions}

The conclusion of the literature review in previous sub-sections is that existing theories do not provide sufficient tools for the construction of a solid framework of determinants that directly affect activity rescheduling behavior. Additionally, empirical findings show that decision making, planning and subsequent activities implementation or its relocation on the agenda, are complex processes. The type of data analyzed, and the nature of the problem addressed in this paper, which requires exploring new determinants of the activity scheduling 
process not identified so far, justified the use of an innovative combination of qualitative and quantitative analysis techniques.

Qualitative methodology is a research approach that allows exploring a phenomenon within its context not only through one lens, but rather a variety of lenses. This characteristic permits to consider a wide range of facets of the phenomenon to be understood. Grounded Theory (Glaser and Strauss, 1967), an interpretative method consisting in generating concepts and hypothesis using inductive analysis, is the most common qualitative approach methodology used in the scarce literature on people travel behavior (Beirão and Cabral, 2007; Carreira, Patrìcio, Jorge, Magee and Hommes, 2013; Gardner and Abraham, 2007; Hannes, Hanssens and Wets, 2008; Simons, Clarys, de Bourdeaudhuij, de Geus, Vandelanotte and Deforche, 2013).

Only Clark and Doherty (2009) have studied activity rescheduling decisions using a qualitative approach. Their work inspired the present study, which includes a number of improvements respect to their research. A larger number of open-ended answers, given by a greater number of respondents, was used. They studied a total of 443 reasons for rescheduling decisions. In contrast, a total of 15,083 reasons for rescheduling decisions were available for the present study. This fact has allowed us to focus on reasons for a single rescheduling decision: pre-planned episodes that are not executed at all (elimination decisions). 2,770 elimination decisions were available in this study, while Clark and Doherty had only 65 decisions related to deletion. In that way, our aim is to identify which determinants are related to high level flexibility in the activity scheduling process. Furthermore, qualitative studies on travel behavior usually lack of any explanation of the process followed to establish neither the codification used nor any justification of the selected qualitative methodological approach. Those aspects are essential to understand the results found in a qualitative study 
(Flick, 2014). In this paper the method used is well justified, and the codification process is detailed.

Moreover, once the main reasons for elimination decisions have been identified, the large dataset available has allowed us to complement the qualitative analysis with a quantitative study. Random Parameter Multivariate Probit models have been utilized to explore which socio-demographic, activity-travel or scheduling-decision factors are associated with each rescheduling reason.

This paper is organized as follows. Next section describes the data used for the analysis. Following section includes the justification of the qualitative and quantitative methodologies used. Then, the analysis of the results obtained from the application of such methods are presented. The paper ends with discussions and conclusions.

\section{Data Set}

A two-wave activity scheduling process panel survey was conducted over a period of two years in the city of Valencia (Spain). The main purposes of that survey were to achieve a better knowledge of the travel mode choice in urban areas and to study the potential effect of Travel Behavior Change Programs (TBCP) on activity-travel scheduling process decisions (Ruiz and García-Garcés, 2014). First and second survey waves took place in autumn 2010 and autumn 2011, respectively.

Respondents were recruited at parking slots in Valencia, while they participated in a survey on willingness to change from car to biking or walking. A total of 165 respondents successfully completed the first survey wave. 47 respondents abandoned the panel because of several reasons, so new respondents were recruited to complete the sample size of the second survey wave. Finally, in the second wave there were 166 participants, and those who participated in both survey waves were 118 individuals. Sample was well balance against 
gender and activity status, but older people were underrepresented (Ruiz and García-Garcés, 2014).

Both survey waves consisted on three phases. First phase was a preliminary face-toface interview to generate a pre-planned activity-travel agenda for the following week starting the day after the interview. Before ending the interview, respondents received a mobile phone with an activity-travel diary implemented. Second phase was developed during the research week, since respondents had to complete the activity-travel diary to collect characteristics (initial time, duration, location, etc.) of activities and trips as executed. Information was sent in real time to the research group, who manually compared pre-planned agenda and observed activities and trips, and identified differences between pre-planned and executed activities and trips. In particular, elimination decisions were defined when activities or trips appeared in the pre-planned agenda and did not appeared in the list of executed episodes. Third phase consisted in an in-depth telephone interview to inquire on the differences found. Some of the questions asked were the following:

- Why did you decide to not carry out/modify/realize that activity/trip?

- When did you decide to not carry out/modify/realize that activity/trip?

- $\quad$ Did the decision depend on another change in a previous activity/trip?

- $\quad$ Did the decision depend on the possibility of carrying out a secondary activity?

- Was the decision taken with/influence by another people?

There were also specific questions attending to the type of decision. In particular, for deletion decisions, respondents were asked if the eliminated activity/trip was going to be carried out in the future. And, if so, when they planned to execute the activity. This information also helped to confirm the definition of deletions decisions made earlier. 
The total number of open-ended answers collected related to episodes added to the agenda in the first survey wave were 7,169. Those open-ended answers related to modified episodes were 5,144. And those open-ended answers related to episodes deleted from the pre-planned agenda were 2,770 (Table 1). In the second survey wave, the number of added episodes were slightly higher, and the number of deleted episodes were slightly lower. As explained before, the focused of this research is on open-ended answers related to the reasons for elimination of activities or trips in the first survey wave.

\section{Table 1}

\section{Methods}

In this paper, an interpretative qualitative method, in particular Analytic Induction (Znaniechi, 1934) (AI), is used to identify determinants of activity-travel re-scheduling decisions. AI is a method of systematic interpretation of events, which includes the process of generating hypothesis as well as testing them (Flick, 2014). This methodology is particularly suitable to expand and generalized an existing theoretical framework from the data analysis. Once those determinants have been identified, econometric models have been used to complement and expand the analysis. In particular, Random Parameter Probit and Multivariate Probit models have been utilized to explore which factors are associated with each determinant.

\subsection{Qualitative Methods}

The data analyzed in this paper are re-scheduling decisions related to not carrying out preplanned activities or trips. Those decisions are also named elimination or deletion of 
activities/trips. There are 2,770 valid answers available to the open-ended question "Why did you decide to not carry out that activity/trip?" which were collected during the in-depth CATI survey of the first panel wave described earlier.

Our methodology is drawn on Taylor and Bogdan’s (1975) version of AI, who proposed several steps to define hypothesis and to recognize themes during the qualitative analysis. Their proposal is adapted to best fit in this research:

1. The first step consisted in defining a coding frame. A coding frame is defined structuring information from the selected material, discovering themes and formulating hypotheses. The information was examined in as many ways as possible in order to understand the general significance of the setting. Open-ended responses were read repeatedly to discover the outlined words and themes. Taking into account these ideas, wider items can be formulated into typologies. This coding frame and the use of theory-based categories result in a first list of codes.

2. The second step was to play down the data to be analyzed within the context in which were collected. People answered accurately to the why question, but sometimes it was referred to an activity or trip carried out previously. In these cases, the responses were out of study because it had been already implemented. The information was obtained through telephone calls every two days. Researchers transcribed the answers taking into account the qualitative framework in which this study was performed.

3. The third step was coding. The objective was to group and analyze the dataset related to certain categories, themes, ideas or concepts. This part of the analysis involved how to differentiate and combine the data retrieved and reflect the information (Miles and Hubermann, 1994). Two researchers coded the same 
dataset and discussed the difficulties, following conventional triangulation procedures. This would support the principle in case study research that the phenomena are viewed and explored from multiple perspectives (Baxter and Jack, 2007). When both sortings were compared, disagreements showed that the code definition was not clear and had to be amended. The data collection and comparison enhanced data quality based on the principles of idea convergence and the confirmation of findings (Knafl and Breitmayer, 1989). To measure the triangulation process, Kappa or percentage of agreement is used. According to Auld et al. (2007) kappa is defined as

$$
\text { Percentage agreement }(\text { kappa })=\frac{\text { agreements }}{\text { agreements }+ \text { disagreements }}
$$

The coding frame or first list of codes included the following determinants or reasons for the elimination of activities or trips: Temporal, Social, Household, Work/Study, Spatial, Weather, and Resources. It was found that some answers could not be sorted in any group. i.e. "Because I went to the hairdresser from work" did not really match in any of those categories. Therefore, a first code revision was performed in order to better adjust to the available responses. So two new codes were proposed: Conflict Scheduling Influence with leisure activities or other maintenance activities (meals, beauty), and Interaction Effects with other (anterior/posterior) activities in the agenda.

Reasons for trips eliminations always referred to the activity that generated those trips, which confirmed the activity-based approach of travel behavior studies. Therefore, after working with the updated coding list, it was realized that it was better to differentiate the 
reasons for activity eliminations from the reasons for trip eliminations. So, it was decided to define two lists of codes for each one. Finally, an agreement was reached considering the following categories:

1. Trip elimination codes:

a) Activity location change: the reason for not carrying out a pre-planned trip is related to a change in the place where the associated activity was going to be performed.

b) Activity suppression: the reason for not carrying out a pre-planned trip is related to not executing the pre-planned anterior or posterior activity, so there is no need to any trip.

2. Activity elimination codes:

a) Social: the decision is related to the influence of other people.

b) Weather: the decision is related to the weather.

c) Mandatory activity: the decision is related to a scheduling conflict with a mandatory activity (work or study).

d) Discretionary activity: the decision is related to a scheduling conflict with an activity that can be performed at the discretion of the individual (recreational, social, games, community/civic activities, volunteer, beauty...).

e) Maintenance activity: the decision is related to a scheduling conflict with activities related to keep the household (shopping, banking, laundry, household and personal chores, appointments, meals, sleeping, pick-up/dropoff activities...).

f) Resources: the decision is related to income, availability of cars, health. 
g) Activity timing/duration: the decision is related to interactions with other activities or trips in the agenda.

h) Location change: the reason for not performing the activity is because the respondent is at a different place to the one in which the episode was preplanned to be carried out.

Researchers met regularly to determine where to code any transcript variations that occurred due to question format. Once the coding structure was finalized, inter-coder reliability was determined by percentage agreement of passages coded. In the comparison, some categories had less than $50 \%$ of agreement. A new revision took place and the coding criteria was refined. For instance, a discrepancy was related to how to take into account different amount of information. An important aspect of respondents' reasoning that emerged from the qualitative analysis is that frequently several motives are behind deletion reasons. For example, a respondent gave the following reason to not carry out a pre-planned activity: " $M y$ son had to prepare some exams and he didn't attend to school so I didn't have to take him there”. That answer was classified in two different codes: social determinant because the reason for eliminating the activity was her son; and a scheduling conflict with a mandatory activity, considering that the new activity to be performed by her son was relevant. Finally, that answer was coded as a social determinant because it was agreed to consider the first reason mentioned in the answer.

The percentage of agreement of the final codification ranged from $78.1 \%$ to $100 \%$. So according to Landis and Koch (1977) the agreement was almost perfect. Moreover, according to Fleiss (1981), the agreement was excellent. A summary of the codification work is presented in Figure 1.

\section{Figure 1}


A careful review of the open-ended questions, in which respondents summarized the reasons behind their deletion decision, let us clarify the schedule decision actually made. Apparent deletion decisions were in fact temporal modifications, or simply pre-planned errors.

Therefore, during the codification process, there were some responses that did not fit in any category. The reasons for not classifying some responses were:

- The answer did not include a clear reason about what had caused the change.

- Some activities or trips were carried out at the same time. In this case, what happened was not a real deletion because both episodes were done although not in a sequential way.

- The activity or trip was already carried out. The episode occurred in the past, so it was not a deletion but a timing modification.

- The activity or trip was carried out with a modification in some of its pre-planned attributes.

- The respondent erred in the pre-planned schedule forgetting some event or situation.

The following table (Table 2) shows some responses belonging to those categories. Hence, subtracting those "out of study" responses, a total of 2,263 open-response data related to reasons for the elimination of trips or activities were analyzed.

\section{Table 2}

\subsection{Quantitative Methods}


In order to carry out a quantitative analysis of the factors that influence the reasons for trips elimination, a process have been considered with two possible outcomes indicated by a dependent binary variable, $y$, taking values 0 (activity suppression) and 1 (activity location change). Demographic and socioeconomic characteristics of the individuals, attributes of the pre-planned and not executed trips, and characteristics of the scheduling process are considered as potential covariates, $x$, which will be used to help explain the occurrence of one outcome or the other.

That binary choice problem was modelled following a latent regression approach, which is specified as

$y^{*}=\beta^{\prime} x+\varepsilon$,

The observed counterpart to $\mathrm{y}^{*}$ is

$\mathrm{y}=1$ if and only if $\mathrm{y}^{*}>0$

$\beta$ are estimable parameters associated with the potential covariates $\mathrm{x}$. The disturbance $\varepsilon$ is assumed to have a normal distribution with mean 0 and variance 1 . This Probit model is estimated using maximum likelihood method.

To account for random heterogeneity in the decisions under investigation, a random parameter model was specified according to the following equation:

$\beta=\bar{\beta}+\Gamma \mathrm{v}$

The equation (4) decomposes each parameter into two parts: one is the average, which is 
fixed and common to all respondents, while the other is a matrix of standard deviations multiplied by an unobservable random term, $\mathrm{v}$, which is independently normally distributed. Nonrandom parameters were accommodated just by placing rows of zeros in the appropriate places in $\Gamma$.

On the other hand, a quantitative analysis of the factors that influence the reasons associated to activities elimination have been carried following a similar modelling framework than trips elimination. However, in this case, five reasons for deletion decisions are included in the model:

$\mathrm{y}_{1}$, whether or not the deletion decision is related to a discretionary activity; y2, whether or not the deletion decision is related to a maintenance activity; $\mathrm{y}_{3}$, whether or not the deletion decision is related to a mandatory activity; $\mathrm{y}_{4}$, whether or not the deletion decision is related to social influence; and $\mathrm{y}_{5}$, whether or not the deletion decision is related to a change in the duration of other preplanned activity.

Each element in the schedule decision vector is recoded as a 0/1 dummy according to whether or not the corresponding schedule decision was made. This recoding of the schedule elimination vector results in a dependent variable that has $2^{5}=32$ distinct states in each analysis. It is assumed that the unobservable propensity of an individual to adopt one of these reasons to not execute a pre-planned activity is systematically related to a set of explanatory variables, via a linear model. Corresponding to these underlying unobservables are the actual observations of whether or not these reasons are in fact adopted. Thus, for each reason to not execute a pre-planned activity:

$$
\mathrm{Py}_{1}=\beta_{1}{ }^{\prime} \mathrm{x}_{1}+\varepsilon_{1}, \quad \text { if } \mathrm{y}_{1}=1, \quad \mathrm{Py}_{1}=0 \quad \text { if } \mathrm{y}_{1}=0
$$




$$
\begin{aligned}
& \mathrm{Py}_{2}=\beta_{2}{ }^{\prime} \mathrm{x}_{2}+\varepsilon_{2}, \quad \text { if } \mathrm{y}_{2}=1, \quad \mathrm{Py}_{2}=0 \quad \text { if } \mathrm{y}_{2}=0
\end{aligned}
$$

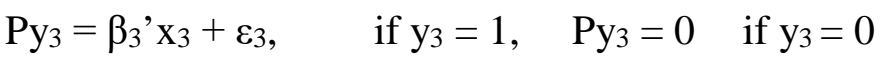

$$
\begin{aligned}
& \mathrm{Py}_{4}=\beta_{4}{ }^{\prime} \mathrm{x}_{4}+\varepsilon 4, \quad \text { if } \mathrm{y}_{4}=1, \quad \mathrm{Py}_{4}=0 \quad \text { if } \mathrm{y}_{4}=0 \\
& \mathrm{Py}_{5}=\beta_{5}{ }^{\prime} \mathrm{x}_{5}+\varepsilon_{5}, \quad \text { if } \mathrm{y}_{5}=1, \quad \mathrm{Py}_{5}=0 \quad \text { if } \mathrm{y}_{5}=0
\end{aligned}
$$

Where

$\mathrm{Py}_{1}=$ unobservable propensity to make a deletion decision related to a discretionary activity $\mathrm{Py}_{2}=$ unobservable propensity to make a deletion decision related to a maintenance activity $\mathrm{Py}_{3}=$ unobservable propensity to make a deletion decision related to a mandatory activity $\mathrm{Py}_{4}=$ unobservable propensity to make a deletion decision related to social influence $\mathrm{Py}_{5}=$ unobservable propensity to make a deletion decision related to a change in the duration of other pre-planned activity.

The quantities $\mathrm{y}_{1}, \mathrm{y}_{2}, \mathrm{y}_{3}, \mathrm{y}_{4}$ and $\mathrm{y}_{5}$, ae discrete $(0,1)$ variables indicating whether the preplanned activity is deleted because a discretionary activity or not, because a maintenance activity or not, because a mandatory activity or not, because a social influence or not, and because a change in the duration of other pre-planned activity or not, respectively. The quantities $x_{i}$ are vectors of (potentially identical) exogenous variables, and $\beta_{i}(i=1, \ldots 5)$ are vectors of estimable parameters associated with the exogenous influences of the incidence of the schedule decision. The correlated error terms $\varepsilon_{\mathrm{i}}(\mathrm{i}=1, \ldots 5)$ are assumed to be drawn from a 
multivariate normal distribution with mean 0 and covariance matrix $\boldsymbol{\Sigma}$. Since the observed data contain no information regarding the magnitude of the underlying propensities, the diagonal elements of $\boldsymbol{\Sigma}$ are normalized to unity; the off-diagonal elements of $\boldsymbol{\Sigma}$ enable the model to accommodate unobserved endogenous effects across the five equations.

These multivariate probit (MVP) systems are simultaneously estimated using weighted least-square with mean and variance correction estimator (WLSMV). The WLSMV is robust against violation of multivariate normality (Greene, 2003).

\section{Qualitative Analysis}

Table 3 presents the characteristics of the activities and trips eliminated, which help to place the results and discussion in context. Mandatory activities are by far the less eliminated. Discretionary and maintenance related activities are eliminated equally. Both activities and trips pre-planned on weekdays are much more eliminated than those pre-planned on weekends are. The later in the day are the activities pre-planned, the more are eliminated, except night activities. In the case of trips, those pre-planned to be performed during the afternoon are the most eliminated. In terms of duration, activities between 30 and 120 minutes and trips shorter than 30 minutes are the most eliminated.

\section{Table 3}

Table 4 shows some responses and their main code or category. As mentioned before, in order to clarify the reasons for the eliminations, trips and activities were studied separately.

\section{Table 4}




\subsection{Reasons for Trips Elimination}

A total of 893 open-ended responses about the reasons for not carrying out a pre-planned trip were available. $75.4 \%$ of those decisions were related to a suppression of the posterior or anterior activity. “They didn't go to the party” [Female, Aged 18-30, 4 household companions, Activity Suppression]. "Because I didn't need to go to meet my girlfriend” [Male, Aged 18-30, Evening, Activity suppression]. The other $24.6 \%$ of decisions related to a trip deletion were caused by a change in the location of the associated activity "We decided to have dinner at home instead of going to the social club” [Female, Aged 31-50, nonhousehold companions, Activity location change]. "I had lunch at my job place” [Female, over 50, Afternoon, Activity location change].

\subsection{Reasons for Activities Elimination}

A total of 1,370 open-ended responses about the reasons for not carrying out a pre-planned activity were available. The most important reason to not carry out a pre-planned activity is related to the influence of other people (20.1\%). Other reasons are scheduling conflicts with activities related to the household maintenance (19.5\%), related to work/study (18.4\%), or to discretionary activities (16.9\%). "I was going to have dinner with friends” [Male, Aged 3150, Social conditioning]. “I had dinner later and then went to sleep” [Male, Aged 18-30, Maintenance activity]. “I had an exam so I stayed studying” [Male, Aged 18-30, Mandatory activity]. “Because I went to have a drink after working” [Female, Aged 18-30, Discretionary activity]. 
An important reason for activity elimination is related to changes in the duration or timing of other activities (15.3\%). “Because I arrived late at home” [Male, Aged 18-30,

Duration/timing] “I stayed longer taking care of my mother” [Female, Aged 31-50, Duration/timing].

Other reasons less mentioned in the open-ended responses are related to resources (4.3\%), location change (4.1\%) and weather (1.5\%). "I had to pick up the replacement car" [Male, Aged 31-50, Resources determinant]. “Because I hadn’t had lunch at home” [Female, Aged 31-50, Location determinant]. "We didn’t go to the park because it was raining” [Female, Aged 18-30, Weather determinant].

\section{Exploratory Analysis}

Table 5 to Table 9 report chi-square values corresponding to independence tests. They check the significance of the categorization defined according to several demographics and characteristics of the activity-travel episodes.

\subsection{Reasons for Trips Elimination}

There are no significant difference on trip deletion decisions by gender (males and females have a similar behavior), nor by age (respondents eliminate trips in a similar way regardless their age). In contrast, reasons for elimination of pre-planned trips are significantly at 5\% level associated to the number and type of companions, according to chi-squared tests results (Table 5).

\section{Table 5}

If the respondent pre-planned to carry out a trip accompanied by more than one household member, activity suppression is only slightly more important than activity location change as 
reasons for the elimination of that trip (55.3\% and $44.7 \%$, respectively). On the other hand, if those one or more companions are non-household related, then the suppression of the anterior or posterior activity is by far the most important reason for the elimination of the trip

Timing is also significantly associated to the reasons for pre-planned trips elimination (Table 6). The main reason for not carrying out a trip is also a suppression of the associated activity, especially if the trip is pre-planned during the evening (81.0\%). But if the trip is preplanned during the afternoon, a change of the location where the posterior activity is going to be realized is slightly more important than the average (30.5\%).

\section{Table 6}

\subsection{Reasons for Activities Elimination}

The reasons for the elimination of pre-planned activities are significantly associated to gender (Table 7). The main reason among females is related to scheduling conflicts with maintenance activities (21.0\%). The influence of other people is also important (19.8\%). On the other hand, the main reason among males for the elimination of a pre-planned activity is related to a scheduling conflict with a mandatory activity (20.9\%). The influence of other people is an important reason as well (20.4\%).

\section{Table 7}

The age of the individual is also significantly associated to the reasons for the elimination of pre-planned activities (Table 6). The most frequent reason to delete a pre-planned activity among those over 50 is related to a scheduling conflict with a maintenance activity (25.8\%). That is also the case for people aged between 31 and 50 (21.9\%). But the influence of other 
people is almost equally important in this later case (21.2\%). Finally, the most frequent reason for the elimination of a pre-planned activity among those aged between 18 and 30 is related to a scheduling conflict with a mandatory activity (21.0\%).

The reasons for the elimination of pre-planned activities are significantly associated to the number and type of companions (Table 8). If the deleted activity was pre-planned to be carried out with more than one companion, the most frequent reason is related to a scheduling conflict with a maintenance activity, especially if the companions are household related (24.8\% and 35.0\%, respectively). On the other hand, reasons for not carrying out a preplanned activity with more than one non-household companions are equally related to the influence of other people and to scheduling conflicts with discretionary activities (22.9\% in both cases). If only one non-household was pre-planned to accompany the individual, then the main reason to not carry out that pre-planned activity is by far related to the influence of other people (41.5\%).

\section{Table 8}

Timing and duration of the pre-planned activity are also significantly associated to the reasons for the elimination of activities (Tables 9 and 10). If the activity is pre-planned to be carried out during the evening or especially during the night, then the main reason to not execute a pre-planned activity is related to a scheduling conflict with a maintenance activity (27.8\% and 39.8\%, respectively). On the other hand, the main reason for the elimination of an activity pre-planned to be carried out during the morning is related to a scheduling conflict with a mandatory activity (26.8\%).

Table 9

Table 10 
The main reason for not carrying out a pre-planned activity with a duration lower than 30 minutes is the influence of other people (42.1\%). In contrast, if the pre-planned duration is between 30 and 120 minutes, the most frequent reason for activity elimination is related to a scheduling conflict with a maintenance activity (21.3\%). If the deleted activity had a preplanned duration larger than 120 minutes, then the main reason is related to a scheduling conflict with a mandatory activity.

\section{Quantitative Analysis}

The specifications of the models were developed by testing the significance of the available socio-economic variables of the respondents' households, several characteristics of the individuals, a number of attributes of the trips and activities implicated and characteristics of the scheduling decision process (Table 11). Nlogit v.5 (Greene, 2003) was used to estimate the Probit model with random parameters and the MVP model. Variables to be included in each model were selected considering their importance outlined in previous research. Then, other variables were tested to check their significance. Multicollinearity was easily detected when a new variable entered in the model was found to be statistically significant while one or more other variables already in the model lost their significance. Non-significant variables were not included in the model specification, because they often display non-structured variation, i.e. noise. Their removal will result in a more stable and robust model. Usually the prediction error decreases as well.

\section{Table 11}

The estimated model parameters, correlation matrix and goodness-of-fit indices are summarized in Tables 12 and 13. The results include for each explanatory variable: coefficient estimates, the ratio of the estimates to their standard errors, and the probability of 
obtaining a greater F statistic than that observed if the null hypothesis is true. The Est./S.E. column can be used to evaluate significance. For example, if the absolute value of the number in this column is greater than 1.96 the estimate can be interpreted as significant at the 0.05 level. Positive coefficients indicate an increased probability of a particular scheduling decision.

\section{Table 12}

\section{Table 13}

\subsection{Reasons for Trips Elimination}

The magnitude of the R-square value obtained for the random parameter probit model specified (Table 12) is common when studying individual travel behavior. Kitamura et al. (1997), in a survey study that included travel diary data for households, found that regressions explaining the number of non-motorized trips undertaken by respondents had Rsquared values ranging from 0.0256 to 0.0428. Similarly, Greenwald and Boarnet (2002), in predicting individual non-work walking trips, found R-squared values ranging from 0.0509 to 0.0848 when using ordinary least squares. Estimated scale parameters are the standard deviations because parameters are normally distributed. Almost all standard deviations are significant, indicating that unobserved heterogeneity is well captured.

Positive signs of the estimated coefficients are associated to an increase of the likelihood of activity location change as the reason to not carry out a pre-planned trip. On the contrary, negative signs are related to a higher chance of deleting the pre-planned trip because the activity that was going to generate that trip was not executed either.

Not executed pre-planned morning trips are more likely to be related to a suppression of the activity that was going to generate that trip. This flexibility associated to morning activity-travel episodes have also been found elsewhere (García-Garcés and Ruiz, 2013). This 
finding may be explained because during the morning, there are more pressure to perform different activities.

Not execution of trips pre-planned to be performed with households' companions are more related to a change in the location of the activity that was going to generate those trips. In contrast, if the trip has been pre-planned to be executed with non-household companions, it is more likely that the reason for not executing that trip is related to activity suppression. Therefore, trips pre-planned with non-household companions are more flexible compare with those pre-planned with household companions. As expected, family influences are stronger than other social influences when keeping their pre-planned agendas.

Pre-planned walking trips are more likely to be not executed because of an activity suppression. On the other hand, if the trip is pre-planned to be performed as a driver companion, then the reason for not executing it is more related to a change in the location. Walking trips are more related to flexible activities than other transportation modes.

Finally, individuals with primary studies are more likely to delete a pre-planned trip because a location change of the activity that was to generate that trip. Low education level is related to less flexible agendas compare with higher levels of education.

\subsection{Reasons for Activities Elimination}

A multivariate probit (MVP) system to explain five reasons to not execute pre-planned activities was simultaneously estimated using weighted least-square with mean and variance correction estimator (WLSMV). The WLSMV is robust against violation of multivariate normality (Greene, 2003).

R-squared value is good, considering that the analyzed information is individual activity-travel data. Several significant correlations among reasons to delete pre-planned activities are found. As expected, reasons related to new activities are correlated whatever 
they are maintenance, mandatory or discretionary. They are also correlated with changing the duration of other activities. Only discretionary activity is correlated with social influence.

To be a son or daughter increases the likelihood of deleting a pre-planned activity because a scheduling conflict with a discretionary activity. This type of activities are more frequently pre-planned and performed by young people than adults. On the other hand, those with non-university higher studies are less likely to delete a pre-planned activity because a scheduling conflict with a discretionary activity. This result is coherent with the previous one, since adults have in general more scheduling conflicts with activities different from discretional.

Activities pre-planned to be executed with household companions are more likely to be deleted from the agenda because a scheduling conflict with a maintenance activity. It is logical to think that household companions can increase the possibility of executing activities related to weekly shopping, pick up and drop off passengers, or personal business. If the activity is pre-planned to be performed in a weekday and not executed, then it is less likely that the reason is associated to a scheduling conflict with a maintenance activity. Therefore, a conclusion could be that maintenance activities, which are mainly carried out on weekdays, have less necessity to substitute any other in the pre-planned agenda to be carried out.

The younger the individual, the more likely is that a mandatory activity impede the execution of a pre-planned one. Mandatory activities are by nature very rigid, and they usually have preference over other types of activities. This is particularly true for young people. Although, according to the results of the model, females have a higher tendency to not perform a pre-planned activity because of a mandatory activity than males. As expected, not executed pre-planned mandatory activities are more likely to be related to scheduling conflicts with a mandatory activity. Similarly, pre-planned activities to be performed in 
weekdays are more likely to be deleted because a scheduling conflict with a mandatory activity.

The older the person, the more likely is that the reason for not executing a pre-planned activity is related to the influence of others. This may be because as people become older, more relationships exists, therefore the probability that any of those social relations influence a change in the activity schedule is higher. Not executed activities pre-planned to be performed during the morning are more likely to be influence by others. This result is coherent with flexible morning trips found in the previous model. If a male makes this scheduling decision, then it is more likely that others had had an influence. This could be interpreted as females being relatively more independent, as also found elsewhere (GarcíaGarcés and Ruiz, 2013). Activities pre-planned to be carried out with non-household companions and not executed are less likely to be related to a social influence. Therefore, people sharing an activity who are not household related have small effect on scheduling changes, as also found previously when studying deletion of trips. Moreover, the more ahead in time was this decision taken, the more likely is that the reason is related to a social influence. This is coherent, considering that deletion decisions taken impulsively are more logically caused by agenda readjustments or other reasons.

Finally, age is negatively related to deletion decisions influenced by changes in timing or duration of other activities. Therefore, young people are more likely to delete pre-planned activities because of adaptations of other activities in their agenda. Males are more inclined to not execute pre-planned activities because of changes in timing or duration of other activities than females. As described earlier, females are more likely to make deletion decisions influenced by other reasons, like mandatory activities. And individuals who share their household are also more likely to delete a pre-planned activity because of changes in timing or duration of other activities. Closer relationships with other household members could 
imply other reasons to make deletion decisions, like accommodating a discretionary activity, as described earlier.

\section{Discussion}

Starting from conceptual frameworks introduced by Hägerstrand (1970), Chapin (1974) and Cullen and Godson (1975), a qualitative approach is used to expand the four "impetus for change” defined by Clark and Doherty (2009) to 10 categories, which reflects several determinants of scheduling decisions related to not execute pre-planned activities or trips.

Before discussing the reasons found for elimination decisions, it is worth mentioning that some open answers provided by respondents were not included in any category because they gave no reason at all for the elimination. This was also the case when an individual explained that the activity-travel episode was executed previously, was going to be carried out subsequently, or was executed at the same time than other activity or trip. Therefore, flexibility was confounded with an elimination decision, which confirms Clark and Doherty's finding based on Cullen and Godson approach.

The elimination of a pre-planned trip is mainly related to the suppression of the activity that had produced that trip. Otherwise, the trip deletion only can be explained by a change in the location where that activity was pre-planned to be performed. This is a logical consequence of the activity based nature of travelling.

On the other hand, the most frequent reason claimed by respondents to not carrying out a pre-planned activity is the influence of other people. This coupling factor had already been identified by Hägerstrand (1970), and also by Clark and Doherty (2009), who named it interpersonal factor. It is then clear that a social network approach could shed more light upon the role of other people on activity rescheduling decisions. 
Reasons for not carrying out a pre-planned activity are also importantly related to scheduling conflicts with other activities. Maintenance, mandatory and discretionary activities have a similar importance. Thanks to a larger sample, those reasons have been studied more in depth than Clark and Doherty. The fact that those three types of activities have a similar relative importance is an indication that other factors (demographics, other facets of the competing activities, etc.) are playing a role in defining execution priority (Doherty, 2006).

Other important reason for the elimination of pre-planned activities is related to changes in timing or duration of the anterior or posterior activity-travel episodes. This result highlights the interrelations among activity-travel episodes included in an individual activity agenda.

Reasons less mentioned by respondents to not carry out a pre-planned activity are related to a lack of resources to execute that activity; a change in the location where the previous activity was performed, which impeded the respondent to execute the activity; and the weather that can obstruct to carry out out-doors. Weather in Valencia during Autumn is warm, and only very sporadic but strong rains alter the situation.

The qualitative research is complemented by a quantitative study to explore which factors influence the reasons found earlier to not carry out a pre-planned activity or trip episode. Contrary to Clark and Doherty findings, our results indicate that demographic and socioeconomics are significantly associated to the reasons for elimination of pre-planned trips and especially activities. This is explained by our larger dataset. The level of education is related to not carry out pre-planned trips because changes in activity location. Females and young individuals are more associated to reasons related to scheduling conflicts with mandatory activities. On the other hand, males and older individuals are more associated to reasons related to influence of other people. Sons and daughters tend to delete pre-planned activities because discretionary activities, while those who share a household make the 
deletion scheduling decision to readjust their agenda while changing timing or duration of other activities.

Moreover, our results also indicate a significant influence of the number and type of companions on the elimination scheduling decision. If the deleted activity was pre-planned to be carried out with more than one companion, the most frequent reason for elimination is related to a scheduling conflict with a maintenance activity, especially if the companions are household related. In contrast, social determinants prevail as most important reason when a few non-household companions are present.

Other characteristics of the deleted activity-travel episodes are significantly associated to the reasons for their elimination as well. Deletions of morning pre-planned trips are more related to suppression of associated activities. And activities pre-planned to be carried out during the morning have reasons for elimination more associated to social influence. Those activities pre-planned to be performed on weekdays are more likely to be deleted because a mandatory activity. Interestingly, the time horizon of the deletion decision is statistically significant: the more ahead it is made, the more likely is that social influence play an important role.

\section{Conclusions}

This paper presents methods and results of a qualitative and quantitative analysis on the activity rescheduling process. First, open-ended answers provided by individuals related to decisions to not carry out pre-planned activities or trips were analyzed using Analytic Induction. The process followed to apply such methodology have been detailed, specifically how the codification that has allowed to categorize all data was established, which facilitated the understanding of the rescheduling reasons. Second, the amount of available data has also permitted to carry out a descriptive and confirmatory statistical study of those reasons, which 
are explained by demographic and socioeconomic characteristics of individuals, attributes of the activity-travel episodes, and characteristics of the scheduling process, identifying some significant associations.

The results presented in this study invite some direct policy implications. For example, congestion management effectiveness could be enhanced through travel behavior change programs (TBCP) that stimulate modifications of the activity agenda associated to sustainable travel. Actions to be included in those TBCP should consider all household members, and/or those with a close tie, to take advantage of the influence of other people in rescheduling decisions. High education and young people usually have agendas that are more flexible. Therefore, including mobility related lessons in education curricula, especially in basic education, could be positive towards promoting sustainable travel behavior. Flexible agendas of sons and daughters are associated to discretionary activities. Parents could take advantage of this result to promote sustainable travel habits when planning out-of-home family leisure activities.

Additionally, as mentioned in the previous section, social networks are important in explaining rescheduling decisions, so they have to be considered both for data collection and analysis and for designing and implementation transportation policies. For example, information campaigns should include social network sites where previously groups of people have been identified. Moreover, the interrelations found between diary and weekly activity-travel episodes suggest that a proper public transportation supply should be designed, in terms of time and space (weekends, low density areas...) so that individuals can accommodate their travel needs along all day/week.

In this study, we have analyzed the first reason mentioned in the open-ended answers. However, a multi-codification of the responses would allow going deeper in the exploration of the main a secondary reasons associated to scheduling changes. Qualitative and 
quantitative analysis of rescheduling decisions related to activities and trips both executed without being pre-planned (additions) and executed including changes in some of their attributes from those pre-planned (modifications) will be carried out in the near future. These analysis will be developed using data available from the first and the second survey waves. A dynamic analysis comparing reasons for scheduling changes before and after Travel Behavior Change Programs (TBCP) were applied will be carried out to find why participants in TBCP could not reduce car use as much as they had pre-planned (Ruiz and García-Garcés, 2014). To properly study the effects of TBCP on the reasons associated to rescheduling decisions, activity-travel data available will be reorganized so that activities and associated trips were linked. 


\section{References}

1. Auld, G. W., A. Diker, and A. Bock. 2007. "Development of a decision tree to determine appropriateness of NVivo in analyzing qualitative data sets.” Journal of nutrition education and behavior 39: 37-47.

2. Auld, J. and A. Mohammadian. 2009. "Framework for the development of the Agentbased Dynamic Activity Planning and Travel Scheduling (ADAPTS) model.” Transportation Letters, The International Journal of Transportation Research 1: 245255.

3. Auld, J. and A. Mohammadian. 2012. “Activity planning processes in the Agent-based Dynamic Activity Planning and Travel Scheduling (ADAPTS) model.” Transportation Research Part A, Policy and Practice 46: 1386-1403.

4. Auld, J., A. Mohammadian, and S.T. Doherty. 2009. “Modeling activity conflict resolution strategies using scheduling process data.” Transportation Research Part A: Policy and Practice, 43: 386-400.

5. Auld, J., T. Rashidi, M. Javanmardiand, and A. Mohammadian. 2011. "Dynamic activity generation model using a competing hazard formulation.” Transportation Research Record: Journal of the Transportation Research Board 2254: 28-35.

6. Axhausen, K. W., and T. Gärling. 1992. “Activity-based appoaches to travel analysis: Conceptual frameworks, models and research problems.” Transport Reviews 12: 323-341.

7. Bandura, A. "Self-Efficacy: Toward a Unifying Theory of Behavioral Change," Psychology Review 84: 191-215.

8. Baxter, P., and S. Jack. 2008. “Qualitative case study methodology: Study design and implementation for novice researchers.” The Qualitative Report 13: 544-559. 
9. Beirão, G., and J. S. Cabral. 2007. "Understanding attitudes towards public transport and private car: a qualitative study.” Transport Policy 14: 478-489.

10. Cao, X., and P. L. Mokhtarian. 2005. "How do individuals adapt their personal travel? Objective and subjective influences on the consideration of travel-related strategies for San Francisco Bay Area commuters.” Transport Policy 12: 291-302.

11. Carreira, R., L. Patrìcio, R. N. Jorge, R. N., C. Magee, and Q. V. Hommes. 2013. “Towards a holistic approach to the travel experience: a qualitative study of bus transportation.” Transport Policy 25: 233-243.

12. Chapin, F. Stuart. 1974. Human activity patterns in the city; things people do in time and in space. New York: Wiley.

13. Chen, C., T. Gärlin, and R. Kitamura. 2004. “Activity rescheduling: reasoned or habitual?” Transportation Research Part F: Traffic Psychology and Behaviour 7: 351371.

14. Chen, C. F., and W. H. Chao. 2011. "Habitual or reasoned? Using the theory of planned behavior, technology acceptance model, and habit to examine switching intentions toward public transit.” Transportation Research Part F: Traffic Psychology and Behaviour 14: $128-137$.

15. Clark, A. F., and S. T. Doherty. 2009. “Activity rescheduling strategies and decision processes in day-to-day life.” Transportation Research Record: Journal of the Transportation Research Board 2134: 143-152.

16. Cools, M. and L. Creemers. 2013. "The dual role of weather forecasts on changes in activity-travel behavior.” Journal of Transport Geography 28: 167-175.

17. Cullen, I. and V. Godson. 1975. "Urban Networks: The Structure of Activity Patterns." Progress in Planning, 4: 1-96. 
18. Doherty, S. T. 2006. “Should we abandon activity type analysis?.” Transportation, 33: 517-536.

19. Doherty, S.T., E. J. Miller, K. W. Axhausen, and T. Gärling. 2002. “A conceptual model of the weekly household activity-travel scheduling process.” In Travel Behaviour: Patterns, Implications and Modelling, edited by E. Stern, I. Salomon, and P. Bovy, 233264. Glos, UK: Edward Elgar.

20. Einhorn, H. J. and R. M. Hogarth. 1981. "Behavioral decision theory: Processes of judgement and choice.” Annual Review of Psychology 32: 53-88.

21. Fleiss, J. 1981. Statistical methods for rates and proportions. New York: John Wiley \& Sons.

22. Flick, U. 2014. An introduction to Qualitative Research. SAGE publications.

23. García-Garcés, P. and T. Ruiz. 2013. "Simultaneous analysis of global decisions in the activity-travel scheduling process.” Transportation Research Record: Journal of the Transportation Research Board, 2328: 121-131.

24. Gardner, B., and C. Abraham. 2007. "What drives car use? A grounded theory analysis of commuters' reasons for driving.” Transportation Research Part F: Traffic Psychology and Behaviour 10: 187-200.

25. Glaser, B. G., and A. L. Strauss. 1967. The discovery of grounded theory: Strategies for qualitative research. Chicago: Aldine.

26. Greene, W. H. 2003. Econometric Analysis. Prentice Hall.

27. Greenwald, M. and M. Boarnet. 2002. "Built Environment as Determinant of Walking Behavior: Analyzing Nonwork Pedestrian Travel in Portland, Oregon.” Transportation Research Record: Journal of the Transportation Research Board 1780: 33-41. 
28. Habib, K. M. N. 2011. “A random utility maximization (RUM) based dynamic activity scheduling model: Application in weekend activity scheduling.” Transportation, 38: 123151.

29. Hägerstrand, T. 1970. "What about people in regional science?.” Papers of the Regional Science Association 24: 7-21.

30. Habib, K. N., A. Sasic, C. Weis, and K. Axhausen. 2013. "Investigating the nonlinear relationship between transportation system performance and daily activity-travel scheduling behavior.” Transportation Research Part A: Policy and Practice 49: 342-357.

31. Hannes, E., D. Janssens, and G. Wets. 2008. "Does space matter? Travel mode scripts in daily activity travel.” Environment and behavior 41: 75-100.

32. Janssens, D., M. Cools, E. Moons, G. Wets, T. Arentze, and H. Timmermans. 2009. "Road Pricing as an Impetus for Environment-Friendly Travel Behavior: Results from a Stated Adaptation Experiment.” Transportation Research Record: Journal of the Transportation Research Board 2115: 50-59.

33. Joh, C. H., S. Doherty, and J. Polak. 2005. “Analysis of factors affecting the frequency and type of activity schedule modification.” Transportation Research Record: Journal of the Transportation Research Board 1926: 19-25.

34. Kademi, E. 2015. "Effects of Pricing Strategies on Dynamic Repertoires of ActivityTravel Behaviour.” PhD diss.. Eindhoven University Press.

35. Kitamura, R., P. Mokhtarian, and L. Laidet. 1997. “A Micro-Analysis of Land Use and Travel in Five Neighborhoods in the San Francisco Bay Area.” Transportation 23: 125158.

36. Knafl, K., and B. Breitmayer. 1991. "Triangulation in qualitative research: Issues of conceptual clarity and purpose.” In Qualitative nursing research: A contemporary dialogue, edited by Janice M. Morse, 226-242. SAGE Publications. 
37. Landis, J. R., and G. Koch. 1977. "The measurement of observer agreement for categorical data.” Biometrics 33: 159-174.

38. Lee, M., and M. G. McNally. 2006.” An empirical investigation on the dynamic processes of activity scheduling and trip chaining.” Transportation, 33: 553-565

39. Milles, M. B., and A. M. Hubermann. 1994. Qualitative data analysis. An expanded sourcebook. SAGE Publications.

40. Nijland, E. W. L., T. A. Arentze, A. W. J. Borgers, and H. J. P. Timmermans. 2009. “Individuals' activity - travel rescheduling behaviour: experiment and model-based analysis.” Environment and Planning A 41: 1511-1522.

41. Roorda M., and B. Andre. 2007. “A stated adaptation survey of activity rescheduling: empirical and preliminary model results.” Transportation Research Record: Journal of the Transportation Research Board, 2021: 45-54.

42. Roorda, M. J., and E. J. Miller. 2005. “Strategies for resolving activity scheduling conflicts: An empirical analysis.” In Progress in Activity-based Analysis, edited by H. J. P. Timmermans, 203-222. Oxford: Elsevier.

43. Ruiz, T., J. Polak, and C. H. Joh. 2005. "Empirical Analysis of Factors Affecting the Resolution of Activity-Scheduling Conflicts.” Transportation Research Record: Journal of the Transportation Research Board, 1926: 50-60.

44. Ruiz, T. and H. Timmermans. 2006a. "Changing the duration of activities in resolving scheduling conflicts.” Transportation Research Part A: Policy and Practice 42: 347-359.

45. Ruiz, T. and H. Timmermans, 2006b. "Changing the timing of activities in resolving scheduling conflicts.” Transportation 33: 429-445.

46. Ruiz, T., and H. Timmermans. 2008. “Changing the duration of activities in resolving scheduling conflicts.” Transportation Research Part A: Policy and Practice 42: 347-359. 
47. Ruiz, T., and M. J. Roorda. 2011. “Assessing planning decisions by activity type during the scheduling process.” Transportmetrica, 7: 417-442.

48. Ruiz, T., and P. García-Garcés. 2014. "Measuring the impact of Travel Behavior Change Programs on the Activity Scheduling Process.” Transportation Letters: The International Journal of Transportation Research, 160: 625-653.

49. Simons, D., P. Clarys, I. De Bourdeaudhuij, B. de Geus, C. Vandelanotte, and B. Deforche. 2013. "Factors influencing mode of transport in older adolescents: a qualitative study.” Public Health, 13:323.

50. Taylor, S., and R. Bogdan. 1975. Introduction to qualitative research method. A phenomenological approach to the social sciences. New York: John Wiley and Sons.

51. van Bladel, K., T. Bellemans, D. Janssens, and G. Wets. 2009. “Activity travel planning and rescheduling behavior. Empirical analysis of influencing factors.” Transportation Research Record: Journal of the Transportation Research Board, 2134, 135-142.

52. Yang, D. 2013. Individual adaptation to Activity-travel repertoires in response to energy price. 13th WCTR, Rio de Janeiro, Brazil.

53. Znaniecki, F. 1934. The method of sociology. New York: Farrar and Rinehart 


\section{FIGURES}

Figure 1. Qualitative model: Results of the codification work

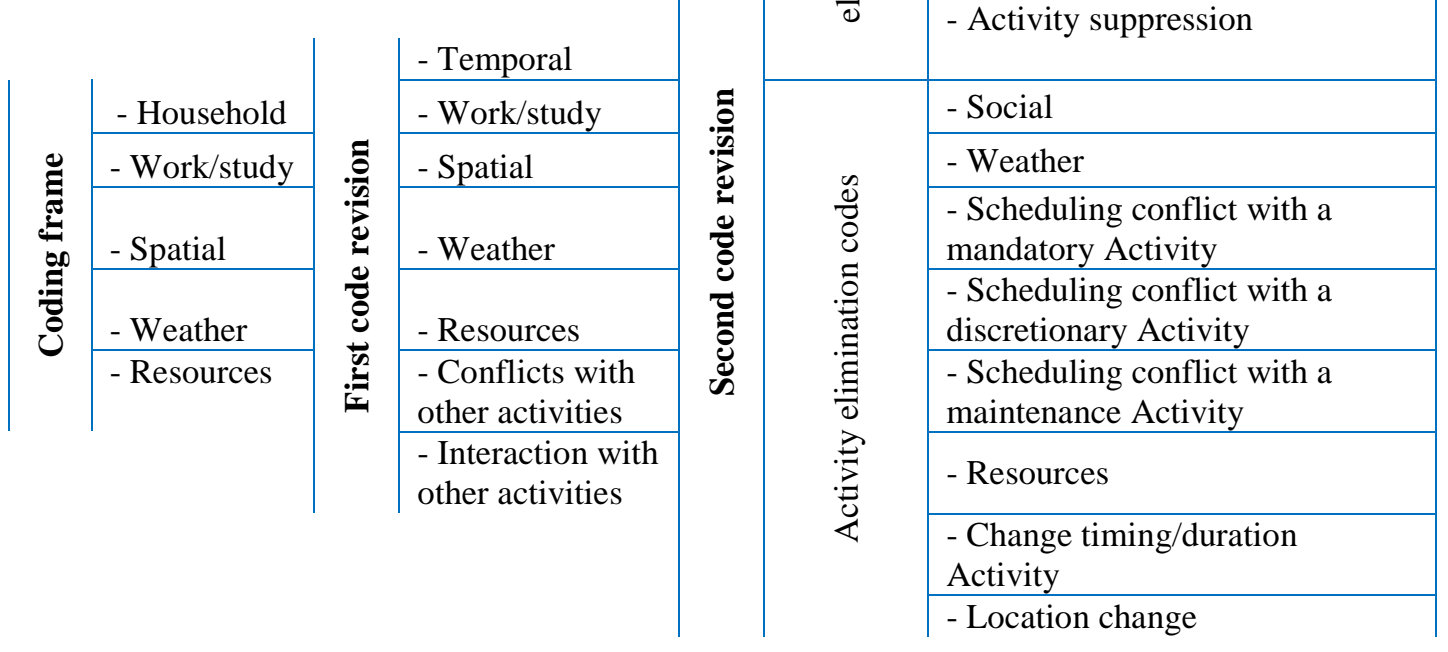




\section{TABLES}

\section{Table 1. Scheduling decisions}

\begin{tabular}{l|rrr|rrr}
\hline & \multicolumn{3}{|c|}{ wave 1 } & \multicolumn{3}{c}{ wave 2 } \\
& activities & trips & total & activities & trips & total \\
\hline planned & 11,225 & 3,780 & 15,005 & 10,493 & 3,229 & 13,722 \\
added & 4,875 & 2,294 & 7,169 & 6,001 & 2,182 & 8,183 \\
modified & 3,363 & 1,781 & 5,144 & 3,805 & 1,540 & 5,345 \\
deleted & 1,677 & 1,093 & 2,770 & 1,012 & 660 & 1,672 \\
executed & 14,438 & 4,967 & 19,405 & 15,144 & 5,089 & 20,233 \\
\hline
\end{tabular}


Table 2. Examples of "out of study" responses

\begin{tabular}{|c|c|c|}
\hline Out of study & Number & Responses \\
\hline \multirow{3}{*}{ Not give a clear reason } & \multirow{3}{*}{234} & "It happened in this way" \\
\hline & & "Eat" \\
\hline & & "It wasn’t needed" \\
\hline \multirow{3}{*}{ Executed at the same time } & \multirow{3}{*}{117} & "I ate something while I was studying" \\
\hline & & "I did it while I was taking care of my daughters" \\
\hline & & "I watched TV while I was having dinner" \\
\hline \multirow{3}{*}{ Already performed } & \multirow{3}{*}{46} & "I had already done it" \\
\hline & & "I did the activity the day before" \\
\hline & & "We had already done the shopping the day before" \\
\hline \multirow{3}{*}{ Modification } & \multirow{3}{*}{59} & "I had dinner in my neighbor’s birthday" \\
\hline & & "I didn't go to my office because I worked at home" \\
\hline & & "I had lunch in the beach" \\
\hline \multirow{3}{*}{ Pre-planning error } & \multirow{3}{*}{51} & "It was Friday afternoon and I normally don't work" \\
\hline & & "I got the plan wrong" \\
\hline & & "I did the activity" \\
\hline Total & 507 & \\
\hline
\end{tabular}


Table 3 Characteristics of the activities and trips eliminated

\begin{tabular}{lcc|lcl}
\hline & Activities & Trips & & Activities & Trips \\
\hline Discretionary & $44.3 \%$ & & Evening & $35.9 \%$ & $28.5 \%$ \\
Maintenance & $41.3 \%$ & & Afternoon & $32.8 \%$ & $35.3 \%$ \\
Mandatory & $14.4 \%$ & & Morning & $25.0 \%$ & $29.5 \%$ \\
& & & Night & $6.3 \%$ & $6.7 \%$ \\
\hline \multirow{2}{*}{ Weekday } & $78.8 \%$ & $81.0 \%$ & & & \\
Weekend & $21.2 \%$ & $19.0 \%$ & $30-120$ min & $16.3 \%$ & $74.1 \%$ \\
& & & $>120$ min & $66.4 \%$ & $25.9 \%$ \\
& & & & & \\
\end{tabular}


Table 4 Examples of coded responses

\begin{tabular}{|c|c|c|c|c|c|c|c|c|c|}
\hline \multicolumn{2}{|r|}{ TRIPS } & \multicolumn{8}{|c|}{ ACTIVITIES } \\
\hline $\begin{array}{c}\text { Activity } \\
\text { suppression } \\
75.4 \%\end{array}$ & $\begin{array}{c}\text { Activity location } \\
\text { change } \\
24.6 \%\end{array}$ & $\begin{array}{c}\text { Social } \\
\text { determinant } \\
20.1 \% \\
\end{array}$ & $\begin{array}{c}\text { Maintenance } \\
\text { activity } \\
19.5 \%\end{array}$ & $\begin{array}{c}\text { Mandatory } \\
\text { activity } \\
18.4 \%\end{array}$ & $\begin{array}{c}\text { Discretionary } \\
\text { activity } \\
16.9 \%\end{array}$ & $\begin{array}{c}\text { Duration/ } \\
\text { timing } \\
15.3 \%\end{array}$ & $\begin{array}{c}\text { Resources } \\
\text { determinant } \\
4.3 \%\end{array}$ & $\begin{array}{c}\text { Location } \\
\text { change } \\
4.1 \%\end{array}$ & $\begin{array}{c}\text { Weather } \\
\text { determinant } \\
1.5 \%\end{array}$ \\
\hline $\begin{array}{l}\text { Because my } \\
\text { class was } \\
\text { cancelled }\end{array}$ & $\begin{array}{l}\text { I remained at home for } \\
\text { dinner }\end{array}$ & $\begin{array}{l}\text { Because my } \\
\text { husband did } \\
\text { the shopping }\end{array}$ & $\begin{array}{l}\text { Because I } \\
\text { stayed at } \\
\text { home having } \\
\text { a nap }\end{array}$ & $\begin{array}{l}\text { He didn't } \\
\text { drop them } \\
\text { off because } \\
\text { he had a } \\
\text { meeting at } \\
\text { work }\end{array}$ & $\begin{array}{l}\text { Because I } \\
\text { went to drink } \\
\text { something } \\
\text { with my } \\
\text { colleagues }\end{array}$ & $\begin{array}{l}\text { Because we } \\
\text { arrived late } \\
\text { at home }\end{array}$ & $\begin{array}{l}\text { I had to pick } \\
\text { up the } \\
\text { replacement } \\
\text { car }\end{array}$ & $\begin{array}{l}\text { Because I } \\
\text { hadn't had } \\
\text { lunch at } \\
\text { home }\end{array}$ & $\begin{array}{l}\text { We didn't go } \\
\text { to the park } \\
\text { because it } \\
\text { was raining }\end{array}$ \\
\hline $\begin{array}{l}\text { I didn't go } \\
\text { to the gym } \\
\text { because I } \\
\text { had a lot of } \\
\text { things to do }\end{array}$ & $\begin{array}{l}\text { Because I decided not to } \\
\text { go to the bar for } \\
\text { breakfast }\end{array}$ & $\begin{array}{l}\text { Some friends } \\
\text { couldn't } \\
\text { meet us that } \\
\text { day and we } \\
\text { changed the } \\
\text { date }\end{array}$ & $\begin{array}{l}\text { My son } \\
\text { started } \\
\text { crying and } \\
\text { we had to } \\
\text { come back } \\
\text { home }\end{array}$ & $\begin{array}{l}\text { I didn't go } \\
\text { to the } \\
\text { university } \\
\text { because they } \\
\text { cancelled } \\
\text { the class }\end{array}$ & $\begin{array}{l}\text { I didn't go for } \\
\text { a walk } \\
\text { because I } \\
\text { stayed at } \\
\text { home } \\
\text { watching the } \\
\text { Soccer World } \\
\text { Championship } \\
\text { on TV }\end{array}$ & $\begin{array}{l}\text { I stayed } \\
\text { longer } \\
\text { taking care } \\
\text { of my mother }\end{array}$ & $\begin{array}{l}\text { I didn't go to } \\
\text { work } \\
\text { because I } \\
\text { was ill }\end{array}$ & $\begin{array}{l}\text { I went to } \\
\text { Zaragoza }\end{array}$ & $\begin{array}{l}\text { Because the } \\
\text { weather was } \\
\text { bad }\end{array}$ \\
\hline $\begin{array}{l}\text { Finally I } \\
\text { didn't visit } \\
\text { my friends } \\
\text { at their } \\
\text { apartment }\end{array}$ & $\begin{array}{l}\text { I decided to stayed } \\
\text { studying at the library }\end{array}$ & $\begin{array}{l}\text { We went to } \\
\text { visit some } \\
\text { friends and } \\
\text { later went to } \\
\text { have dinner }\end{array}$ & $\begin{array}{l}\text { I was too } \\
\text { tired to go to } \\
\text { the gym }\end{array}$ & $\begin{array}{l}\text { He had to } \\
\text { work }\end{array}$ & $\begin{array}{l}\text { We decided to } \\
\text { go out and } \\
\text { have a drink }\end{array}$ & $\begin{array}{l}\text { Because I } \\
\text { woke up late }\end{array}$ & $\begin{array}{l}\text { I didn't go to } \\
\text { the gym } \\
\text { because I } \\
\text { had an ankle } \\
\text { injured }\end{array}$ & $\begin{array}{l}\text { I didn't } \\
\text { prepare the } \\
\text { meal } \\
\text { because I } \\
\text { had lunch } \\
\text { out of home }\end{array}$ & It had rained \\
\hline $\begin{array}{l}\text { Because I } \\
\text { didn't have } \\
\text { to work } \\
\text { during the } \\
\text { morning }\end{array}$ & $\begin{array}{l}\text { Because I had lunch at } \\
\text { my workplace }\end{array}$ & $\begin{array}{l}\text { Because my } \\
\text { friends } \\
\text { couldn't } \\
\text { do it }\end{array}$ & $\begin{array}{l}\text { I had to take } \\
\text { care of my } \\
\text { daughter }\end{array}$ & $\begin{array}{l}\text { Because the } \\
\text { client } \\
\text { cancelled } \\
\text { the } \\
\text { appointment }\end{array}$ & $\begin{array}{l}\text { I didn't visit } \\
\text { my father } \\
\text { because I } \\
\text { decided to go } \\
\text { to the beach }\end{array}$ & $\begin{array}{l}\text { Because I } \\
\text { arrived } \\
\text { home later } \\
\text { than I } \\
\text { expected }\end{array}$ & $\begin{array}{l}\text { Because I } \\
\text { had a tattoo } \\
\text { and I have } \\
\text { been told } \\
\text { that I } \\
\text { couldn't } \\
\text { swear }\end{array}$ & $\begin{array}{l}\text { I went out to } \\
\text { have dinner } \\
\text { and I arrived } \\
\text { late at home }\end{array}$ & $\begin{array}{l}\text { We didn't go } \\
\text { for a walk } \\
\text { because it } \\
\text { was very } \\
\text { cold }\end{array}$ \\
\hline
\end{tabular}


Table 5 Reasons for trips elimination by number and type of companion

\begin{tabular}{|c|c|c|c|c|c|c|c|c|c|c|c|c|}
\hline & \multicolumn{6}{|c|}{ Household companions } & \multicolumn{6}{|c|}{ Non-household conpanions } \\
\hline & \multicolumn{2}{|c|}{ One person } & \multicolumn{2}{|c|}{ + One person } & \multicolumn{2}{|c|}{ Total } & \multicolumn{2}{|c|}{ One person } & \multicolumn{2}{|c|}{ + One person } & \multicolumn{2}{|c|}{ Total } \\
\hline & Resp & $\%$ & Resp & $\%$ & Resp & $\%$ & Resp & $\%$ & Resp & $\%$ & Resp & $\%$ \\
\hline $\begin{array}{l}\text { Activity } \\
\text { suppression }\end{array}$ & 105 & $71.9 \%$ & 21 & $55.3 \%$ & 126 & $68.5 \%$ & 75 & $78.1 \%$ & 41 & $93.2 \%$ & 116 & $82.9 \%$ \\
\hline $\begin{array}{l}\text { Activity } \\
\text { Location } \\
\text { change }\end{array}$ & 41 & $28.1 \%$ & 17 & $44.7 \%$ & 58 & $31.5 \%$ & 21 & $21.9 \%$ & 3 & $6.8 \%$ & 24 & $17.1 \%$ \\
\hline \multirow[t]{2}{*}{ Total } & 146 & & 38 & & 184 & & 96 & & 44 & & 140 & \\
\hline & \multicolumn{6}{|c|}{$\chi 2=3.875$, d.f. $=1, \mathrm{p}<0.049, \mathrm{n}=184$} & \multicolumn{4}{|c|}{$\chi^{2}=4.816$, d.f. $=1, \mathrm{p}<0.028, \mathrm{n}=140$} & & \\
\hline
\end{tabular}


Table 6 Reasons for trips elimination by timing

\begin{tabular}{|c|c|c|c|c|c|c|c|c|c|c|}
\hline & \multicolumn{2}{|c|}{ Morning } & \multicolumn{2}{|c|}{ Afternoon } & \multicolumn{2}{|c|}{ Evening } & \multicolumn{2}{|c|}{ Night } & \multicolumn{2}{|c|}{ Total } \\
\hline & Resp & $\%$ & Resp & $\%$ & Resp & $\%$ & Resp & $\%$ & Resp & $\%$ \\
\hline $\begin{array}{l}\text { Activity } \\
\text { suppression }\end{array}$ & 198 & $78.6 \%$ & 210 & $69.5 \%$ & 192 & $81.0 \%$ & 43 & $71.7 \%$ & 643 & $75.6 \%$ \\
\hline $\begin{array}{l}\text { Location } \\
\text { change }\end{array}$ & 54 & $21.4 \%$ & 92 & $30.5 \%$ & 45 & $19.0 \%$ & 17 & $28.3 \%$ & 208 & $24.4 \%$ \\
\hline \multirow[t]{2}{*}{ Total } & 252 & & 302 & & 237 & & 60 & & 851 & \\
\hline & \multicolumn{8}{|c|}{$\chi^{2}=11.479$, d.f. $=3, \mathrm{p}<0.009, \mathrm{n}=851$} & & \\
\hline
\end{tabular}


Table 7 Reasons for activities elimination by gender and age

\begin{tabular}{|c|c|c|c|c|c|c|c|c|c|c|c|c|}
\hline & \multicolumn{4}{|c|}{ Gender } & \multicolumn{6}{|c|}{ Age } & \multicolumn{2}{|c|}{ Total } \\
\hline & \multicolumn{2}{|c|}{ Male } & \multicolumn{2}{|c|}{ Female } & \multicolumn{2}{|c|}{$18-30$} & \multicolumn{2}{|c|}{$31-50$} & \multicolumn{2}{|c|}{+50} & \multirow[b]{2}{*}{ Resp } & \multirow[b]{2}{*}{$\%$} \\
\hline & Resp & $\%$ & Resp & $\%$ & Resp & $\%$ & Resp & $\%$ & Resp & $\%$ & & \\
\hline Social & 145 & $20.4 \%$ & 130 & $19.8 \%$ & 105 & $18.3 \%$ & 142 & $21.2 \%$ & 28 & $22.6 \%$ & 275 & $20.1 \%$ \\
\hline Maintenance & 129 & $18.1 \%$ & 138 & $21.0 \%$ & 88 & $15.3 \%$ & 147 & $21.9 \%$ & 32 & $25.8 \%$ & 267 & $19.5 \%$ \\
\hline Mandatory & 149 & $20.9 \%$ & 103 & $15.7 \%$ & 121 & $21.0 \%$ & 111 & $16.5 \%$ & 20 & $16.1 \%$ & 252 & $18.4 \%$ \\
\hline Discretionary & 112 & $15.7 \%$ & 119 & $18.1 \%$ & 89 & $15.5 \%$ & 119 & $17.7 \%$ & 23 & $18.5 \%$ & 231 & $16.9 \%$ \\
\hline Duration & 100 & $14.0 \%$ & 110 & $16.7 \%$ & 105 & $18.3 \%$ & 93 & $13.9 \%$ & 12 & $9.7 \%$ & 210 & $15.3 \%$ \\
\hline Resources & 36 & $5.1 \%$ & 23 & $3.5 \%$ & 20 & $3.5 \%$ & 35 & $5.2 \%$ & 4 & $3.2 \%$ & 59 & $4.3 \%$ \\
\hline $\begin{array}{l}\text { Location } \\
\text { change }\end{array}$ & 27 & $3.8 \%$ & 29 & $4.4 \%$ & 39 & $6.8 \%$ & 13 & $1.9 \%$ & 4 & $3.2 \%$ & 56 & $4.1 \%$ \\
\hline Weather & 14 & $2.0 \%$ & 6 & $0.9 \%$ & 8 & $1.4 \%$ & 11 & $1.6 \%$ & 1 & $0.8 \%$ & 20 & $1.5 \%$ \\
\hline Total & 712 & & 658 & & 575 & & 671 & & 124 & & 1,370 & \\
\hline \multicolumn{5}{|c|}{$\chi 2=14.236$, d.f. $=7, \mathrm{p}<0.047, \mathrm{n}=1,370$} & \multicolumn{6}{|c|}{$\chi 2=44.257$, d.f. $=14, \mathrm{p}<0.000, \mathrm{n}=1,370$} & & \\
\hline
\end{tabular}


Table 8 Reasons for activities elimination by number and type of companion

\begin{tabular}{|c|c|c|c|c|c|c|c|c|c|c|c|c|}
\hline & \multicolumn{6}{|c|}{ Household companions } & \multicolumn{6}{|c|}{ Non-household conpanions } \\
\hline & \multicolumn{2}{|c|}{ One person } & \multicolumn{2}{|c|}{ + One person } & \multicolumn{2}{|c|}{ Total } & \multicolumn{2}{|c|}{ One person } & \multicolumn{2}{|c|}{ + One person } & \multicolumn{2}{|c|}{ Total } \\
\hline & Resp & $\%$ & Resp & $\%$ & Resp & $\%$ & Resp & $\%$ & Resp & $\%$ & Resp & $\%$ \\
\hline Social & 54 & $24.3 \%$ & 43 & $35.0 \%$ & 97 & $28.1 \%$ & 44 & $41.5 \%$ & 27 & $22.9 \%$ & 71 & $31.7 \%$ \\
\hline Discretionary & 51 & $23.0 \%$ & 19 & $15.4 \%$ & 70 & $20.3 \%$ & 20 & $18.9 \%$ & 27 & $22.9 \%$ & 47 & $21.0 \%$ \\
\hline Mandatory & 46 & $20.7 \%$ & 16 & $13.0 \%$ & 62 & $18.0 \%$ & 8 & $7.5 \%$ & 23 & $19.5 \%$ & 31 & $13.8 \%$ \\
\hline Maintenance & 28 & $12.6 \%$ & 26 & $21.1 \%$ & 54 & $15.7 \%$ & 12 & $11.3 \%$ & 18 & $15.3 \%$ & 30 & $13.4 \%$ \\
\hline Duration & 30 & $13.5 \%$ & 14 & $11.4 \%$ & 44 & $12.8 \%$ & 12 & $11.3 \%$ & 7 & $5.9 \%$ & 19 & $8.5 \%$ \\
\hline Resources & 6 & $2.7 \%$ & 1 & $0.8 \%$ & 7 & $2.0 \%$ & 7 & $6.6 \%$ & 11 & $9.3 \%$ & 18 & $8.0 \%$ \\
\hline Weather & 5 & $2.3 \%$ & 2 & $1.6 \%$ & 7 & $2.0 \%$ & 3 & $2.8 \%$ & 4 & $3.4 \%$ & 7 & $3.1 \%$ \\
\hline Location change & 2 & $0.9 \%$ & 2 & $1.6 \%$ & 4 & $1.2 \%$ & 0 & $0.0 \%$ & 1 & $0.8 \%$ & 1 & $0.4 \%$ \\
\hline \multirow[t]{2}{*}{ Total } & 222 & & 123 & & 345 & & 106 & & 118 & & 224 & \\
\hline & \multicolumn{4}{|c|}{$\begin{array}{c}\chi^{2}=13.875, \text { d.f. }=7, p<0.053 \\
n=345\end{array}$} & & & \multicolumn{4}{|c|}{$\begin{array}{c}\chi 2=16.323, \text { d.f. }=7, p<0.022 \\
n=224\end{array}$} & & \\
\hline
\end{tabular}


Table 9 Reasons for activities elimination by timing

\begin{tabular}{|c|c|c|c|c|c|c|c|c|c|c|}
\hline & \multicolumn{2}{|c|}{ Morning } & \multicolumn{2}{|c|}{ Afternoon } & \multicolumn{2}{|c|}{ Evening } & \multicolumn{2}{|c|}{ Nigth } & \multicolumn{2}{|c|}{ Total } \\
\hline & Resp & $\%$ & Resp & $\%$ & Resp & $\%$ & Resp & $\%$ & Resp & $\%$ \\
\hline Social & 60 & $17.6 \%$ & 105 & $23.9 \%$ & 87 & $19.8 \%$ & 11 & $13.8 \%$ & 263 & $20.2 \%$ \\
\hline Maintenance & 53 & $15.6 \%$ & 84 & $19.1 \%$ & 96 & $21.8 \%$ & 25 & $31.3 \%$ & 258 & $19.8 \%$ \\
\hline Mandatory & 91 & $26.8 \%$ & 88 & $20.0 \%$ & 52 & $11.8 \%$ & 5 & $6.3 \%$ & 236 & $18.2 \%$ \\
\hline Discretionary & 37 & $10.9 \%$ & 78 & $17.7 \%$ & 93 & $21.1 \%$ & 15 & $18.8 \%$ & 223 & $17.2 \%$ \\
\hline Duration & 76 & $22.4 \%$ & 40 & $9.1 \%$ & 66 & $15.0 \%$ & 13 & $16.3 \%$ & 195 & $15.0 \%$ \\
\hline Resources & 17 & $5.0 \%$ & 15 & $3.4 \%$ & 16 & $3.6 \%$ & 7 & $8.8 \%$ & 55 & $4.2 \%$ \\
\hline Location change & 3 & $0.9 \%$ & 23 & $5.2 \%$ & 26 & $5.9 \%$ & 2 & $2.5 \%$ & 54 & $4.2 \%$ \\
\hline Weather & 3 & $0.9 \%$ & 7 & $1.6 \%$ & 4 & $0.9 \%$ & 2 & $2.5 \%$ & 16 & $1.2 \%$ \\
\hline \multirow[t]{2}{*}{ Total } & 340 & & 440 & & 440 & & 80 & & 1,300 & \\
\hline & \multicolumn{8}{|c|}{$\chi 2=101.764$, d.f. $=21, \mathrm{p}<0.000, \mathrm{n}=1,300$} & & \\
\hline
\end{tabular}


Table 10 Reasons for activities elimination by duration

\begin{tabular}{l|cccccc|cc}
\hline & \multicolumn{2}{|c}{$<\mathbf{3 0}$ min } & \multicolumn{3}{c|}{$\mathbf{3 0}-\mathbf{1 2 0}$ min } & \multicolumn{2}{c|}{$\mathbf{1 2 0}$ min } & \multicolumn{2}{c}{ Total } \\
& Resp & $\mathbf{\%}$ & Resp & \% & Resp & \% & Resp & \% \\
\hline Social & 90 & $42.1 \%$ & 120 & $14.8 \%$ & 40 & $17.3 \%$ & 250 & $19.9 \%$ \\
Maintenance & 29 & $13.6 \%$ & 173 & $21.3 \%$ & 44 & $19.0 \%$ & 246 & $19.6 \%$ \\
Mandatory & 37 & $17.3 \%$ & 133 & $16.4 \%$ & 60 & $26.0 \%$ & 230 & $18.3 \%$ \\
Discretionary & 15 & $7.0 \%$ & 152 & $18.7 \%$ & 52 & $22.5 \%$ & 219 & $17.4 \%$ \\
Duration & 23 & $10.7 \%$ & 151 & $18.6 \%$ & 16 & $6.9 \%$ & 190 & $15.1 \%$ \\
Location change & 13 & $6.1 \%$ & 35 & $4.3 \%$ & 5 & $2.2 \%$ & 53 & $4.2 \%$ \\
Resources & 6 & $2.8 \%$ & 35 & $4.3 \%$ & 12 & $5.2 \%$ & 53 & $4.2 \%$ \\
Weather & 1 & $0.5 \%$ & 12 & $1.5 \%$ & 2 & $0.9 \%$ & 15 & $1.2 \%$ \\
\hline Total & 214 & & 811 & & 231 & & 1,256 & \\
\hline
\end{tabular}


Table 11. Dependent and explanatory variables in quantitative analysis

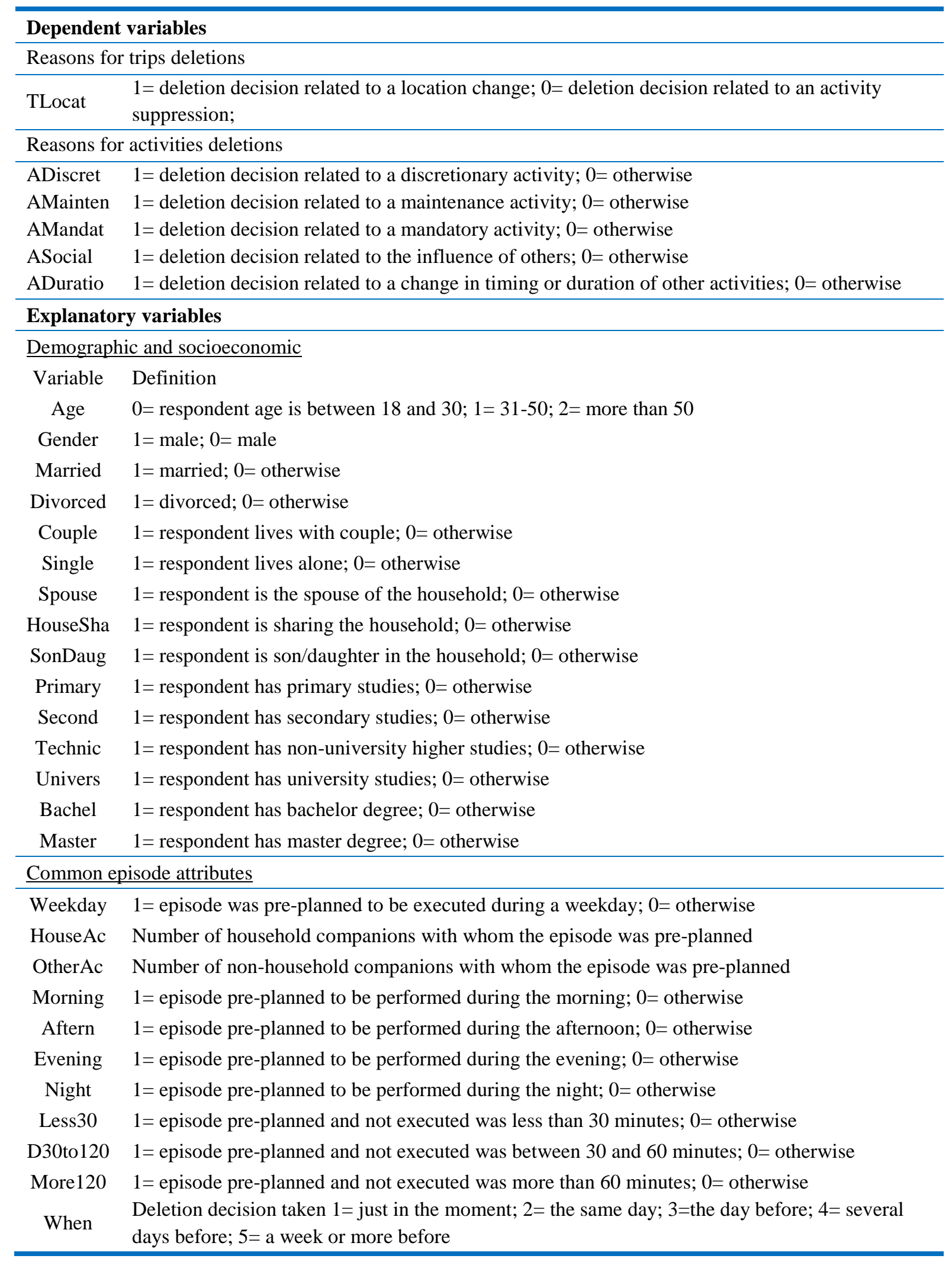


Table 11. Dependent and explanatory variables in quantitative analysis (Cont.)

$\underline{\text { Trip attributes }}$

Walking $1=$ walking trip pre-planned; $0=$ otherwise

Bike $\quad 1=$ cycling trip pre-planned; $0=$ otherwise

CarDriv $1=$ car driving trip pre-planned; $0=$ otherwise

CarComp $1=$ car driving companion trip pre-planned; $0=$ otherwise

MotoDriv $1=$ moto driving trip pre-planned; $0=$ otherwise

UrbanBus $1=$ trip pre-planned by bus; $0=$ otherwise

Metro $1=$ walking trip pre-planned by metro; $0=$ otherwise

Taxi $1=$ walking trip pre-planned by taxi; $0=$ otherwise

Activity attributes

Mandat 1= activity type is mandatory; 0 otherwise

Mainten 1= activity type is maintenance; 0 otherwise

Discret $1=$ activity type is discretionary; 0 otherwise 
Table 12. Random Parameter Probit Model for Trips Deletions Reasons

\begin{tabular}{llrr}
\hline & Coefficient & b/St.Er. & $\mathrm{P}\left[|\mathrm{z}|>\mathrm{Z}^{*}\right]$ \\
\hline Means for random parameters & & & \\
\hline Constant & $-2.58792^{* * *}$ & -10.6 & 0 \\
Morning & $-0.86424^{* * *}$ & -3.83 & 0.0001 \\
HouseAc & $0.92567^{* * *}$ & 5.83 & 0 \\
OtherAc & $-0.87389^{* * *}$ & -4.06 & 0 \\
Walking & $-0.71150^{*}$ & -1.95 & 0.0514 \\
CarComp & $1.83519^{* * *}$ & 3.02 & 0.0025 \\
Primary & $1.21857^{* *}$ & 2.10 & 0.0354 \\
\hline Scale parameters for dists. of random parameters & & \\
\hline Constant & $3.21583^{* * *}$ & 11.15 & 0 \\
Morning & $0.54481^{* * *}$ & 2.89 & 0.0039 \\
HouseAc & $0.24785^{* *}$ & 1.99 & 0.0461 \\
OtherAc & 0.12546 & 0.68 & 0.4953 \\
Walking & $5.52846^{* * *}$ & 8.29 & 0 \\
CarComp & $2.23834^{* * *}$ & 3.25 & 0.0011 \\
Primary & $2.98762^{* * *}$ & 3.96 & 0.0001 \\
\hline Sample size & 886 & & \\
\hline Restricted log likelihood & -434.29398 & & \\
\hline Log likelihood & -419.52272 & & \\
\hline R-squared & 0.0352 & & \\
\hline Not & & & \\
\hline
\end{tabular}

Note: ${ }^{* * *}, * *, *$ Significance at $1 \%, 5 \%, 10 \%$ level 
Table 13. Multivariate Probit Model for Activities Deletions Reasons

\begin{tabular}{|c|c|c|c|c|c|c|c|}
\hline & Coefficient & b/St.Er. & $\mathrm{P}[|\mathrm{z}|>\mathrm{Z} *]$ & & Coefficient & b/St.Er. & $\mathrm{P}\left[|\mathrm{z}|>\mathrm{Z}^{*}\right]$ \\
\hline \multicolumn{4}{|c|}{ Index function for ADiscret (01) } & \multicolumn{4}{|c|}{ Index function for Asocial (04) } \\
\hline Constant & $-1.13891^{* * *}$ & -19.61 & 0 & Constant & $-0.48516^{* * *}$ & -8.09 & 0 \\
\hline Sondaug & $0.20867 * *$ & 2.45 & 0.0145 & Age & $0.16514^{* * *}$ & 3.1 & 0.0019 \\
\hline Technic & $-0.63518 *$ & -1.84 & 0.0651 & Morning & $0.00026^{*}$ & 1.74 & 0.0825 \\
\hline \multicolumn{4}{|c|}{ Index function for AMaintein (02) } & Gender & $0.14379 * *$ & 2.22 & 0.0265 \\
\hline Constant & $-0.47941^{* * * *}$ & -6.15 & 0 & OtherAc & $-0.00031^{*}$ & -1.67 & 0.0942 \\
\hline HouseAc & $0.00045^{* *}$ & 2.02 & 0.0437 & When & $0.00077^{*}$ & 1.65 & 0.0995 \\
\hline Weekday & $-.17416^{* *}$ & -2.04 & 0.0416 & & & & \\
\hline \multicolumn{4}{|c|}{ Index function for AMandat (03) } & \multicolumn{4}{|c|}{ Index function for ADuratio (05) } \\
\hline Constant & $-1.12207^{* * *}$ & -11.14 & 0 & Constant & $-0.84198 * * *$ & -12.26 & 0 \\
\hline Age & $-.15355 * * *$ & -2.73 & 0.0064 & Age & $-0.12212^{*}$ & -1.94 & 0.0522 \\
\hline Gender & $-0.21963 * * *$ & -3.22 & 0.0013 & Gender & $0.21539 * * *$ & 2.91 & 0.0037 \\
\hline Mandat & $0.00065^{*}$ & 1.94 & 0.0528 & HouseSha & $0.62943^{* * *}$ & 0.13 & 0 \\
\hline Weekday & $0.55970 * * *$ & 5.14 & 0 & & & & \\
\hline \multicolumn{4}{|c|}{ Correlation coefficients } & \multicolumn{4}{|c|}{ Correlation coefficients } \\
\hline $\mathrm{R}(01,02)$ & $-0.46788 * * *$ & -10.32 & 0 & $\mathrm{R}(03,04)$ & $-0.44007 * * *$ & -8.51 & 0 \\
\hline $\mathrm{R}(01,03)$ & $-0.38400 * * *$ & -8.53 & 0 & $\mathrm{R}(01,05)$ & $-0.23955 * * *$ & -3.63 & 0.0003 \\
\hline $\mathrm{R}(02,03)$ & $-0.40483^{* * *}$ & -8.81 & 0 & $\mathrm{R}(02,05)$ & -0.04116 & -0.68 & 0.4946 \\
\hline $\mathrm{R}(01,04)$ & -0.04411 & -0.82 & 0.4144 & $\mathrm{R}(03,05)$ & $0.17555^{* * *}$ & 3.44 & 0.0006 \\
\hline $\mathrm{R}(02,04)$ & -0.03063 & -0.6 & 0.5457 & $\mathrm{R}(04,05)$ & $-0.33051^{* * *}$ & -5.35 & 0 \\
\hline \multicolumn{3}{|c|}{$\begin{array}{ll}\text { Sample size } & 1436\end{array}$} & & & & & \\
\hline \multicolumn{2}{|c|}{ Restricted Log Likelihood } & -3939.2784 & & & & & \\
\hline \multicolumn{2}{|c|}{ Log Likelihood } & -3469.6495 & & & & & \\
\hline \multicolumn{2}{|c|}{ Pseudo R2 } & 0.13535 & & & & & \\
\hline \multicolumn{2}{|l|}{ AIC } & 7001.3 & & & & & \\
\hline
\end{tabular}

Note: $* * *, * *, *$ Significance at $1 \%, 5 \%, 10 \%$ level 